\title{
Investigating the Effect of Wettability on Sand Production in the Presence of Smart Water and Smart Nanofluid: an Experimental Study
}

\author{
Afshin Bahri ${ }^{\text {(D) }}$, Ehsan Khamehchi ${ }^{1, *(D)}$ \\ 1 Department of Petroleum Engineering, Amirkabir University of Technology (Tehran Polytechnic), Tehran, Iran \\ * Correspondence: khamehchi@aut.ac.ir (E.K.)
}

Scopus Author ID 26657370700

Received: 9.01.2021; Revised: 7.02.2021; Accepted: 9.02.2021; Published: 13.02.2021

\begin{abstract}
In recent years, research activity to increase oil recovery from hydrocarbon reservoirs by smart water (SW) injection has risen sharply. Smart water injection is one of the most efficient and lowcost methods in the improved and enhanced oil recovery (IOR/EOR) process. One of the active mechanisms of smart water to increase the oil production is wettability alteration of the rock surface from oil-wet to water-wet conditions. Recently smart water injection into unconsolidated sandstone reservoirs due to disturbance of the rock surface equilibrium causes instability of formation particles and sand production. One of the main factors disturbing the equilibrium and sand production is the sandstone surface's wettability alteration mechanism caused by disjoining pressure and stresses on the rock surface. Reduction of the reservoir permeability and closure of fluid flow paths and consequent reduction of oil production are among the main damages of sand production. In this study, a complete study on optimum smart water design based on the least sedimentation due to mixing has been done by formation water compatibility tests and analysis on divalent ions through the Taguchi design. Then the water wet sandstones were converted to oil-wet condition by model oil (stearic acid + normal heptane) in different concentrations. The wettability effect of water wet, neutral wet oil-wet on the amount of sand production in the presence of smart water in the reservoir conditions was fully investigated. To prevent sand production, a very effective chemical method of nanoparticles was used. By stabilizing silica nanoparticles $\left(\mathrm{SiO}_{2}\right)$ with an optimum concentration of $2000 \mathrm{ppm}$ in smart water $(\mathrm{pH}=8)$, according to the results of the zeta potential and Dynamic light scattering (DLS) test, the effect of wettability on sand production in the presence of smart nanofluid was fully investigated. The test results show a significant reduction in sand production and a rapid wettability alteration towards smart nanofluids' water-wet conditions. This indicates the improvement of fluid for enhanced oil recovery processes in unconsolidated sandstone reservoirs.
\end{abstract}

Keywords: sand production; smart water (SW); smart nanofluid; silica nanoparticles $\left(\mathrm{SiO}_{2}\right)$; wettability alteration; zeta potential.

(C) 2021 by the authors. This article is an open-access article distributed under the terms and conditions of the Creative Commons Attribution (CC BY) license (https://creativecommons.org/licenses/by/4.0/).

\section{Introduction}

Sandstone reservoirs are one of the most important types of oil reservoirs around the world. Sandstone mainly consists of quartz, feldspar, and clay minerals (kaolinite, illite, smectite, and chlorite) [1,2]. The quality of sandstone reservoirs depends on their porosity and permeability, which depends on the rock's texture and cementation. The dissolution process in these reservoirs results from the leaching of cement and unstable particles such as feldspar, for which sand production is one of the reservoir's problems [3]. This phenomenon, in which sand https://biointerfaceresearch.com/ 
particles are separated from the reservoir rock following high pressures, imposes high oil companies' costs each year. Erosion and blocking of surface and intra-well equipment and reduction of reservoir permeability, and subsequent decrease of recovery factor (RF) are some of the important problems of sand production [4-6].

The geochemical complexity causes wettability alteration in sandstones to encompass a wide range from very strong water-wet to very strong oil-wet [7]. The sandstone surface has a negative electric charge within the reservoirs' natural $\mathrm{pH}$ range [8]. One of the factors that significantly impact the migration of formation particles is the surface rock's wettability properties [9]. Various researchers have conducted experiments in the two-phase flow state in porous media and, it has been concluded that the movement of the surface wetting phase is necessary for the migration of formation particles [10, 11].

However, considering that most of the world's oil reservoirs have entered the secondary and tertiary recovery periods, the residual oil production in the reservoirs has been found after primary recovery. Low salinity water flooding (LSWF) or controlled salinity water flooding (CSWF), commonly known as smart water (SW), is proposed as a highly efficient method in IOR/EOR [12-14]. Smart water, having created changes in the composition and concentration of salts in water, has led the injection fluid towards more compatibility with rock and fluids reservoir. However, with low salinity water, only primary water salinity (seawater) decreased to a ratio, so low salinity water can be considered as a kind of smart water [15-17].

The use of smart water changes the reservoir rock's wettability. It brings it to the desired wettability by changing the salinity of water injection into the reservoir and using specific ions utilized in the smart water composition $[18,19]$. A reservoir rock can have three types of wettability; 1- water-wet (WW): reservoir rock tends to spread water on its surface. 2- oil-wet $(\mathrm{OW})$ : the oil phase is spread on the rock surface. 3- neutral-wet $(\mathrm{NW})$ : rock has the same tendency to spread water and oil on its surface. This property is investigated by measuring the contact angle formed by the fluid and the rock surface. The classification of wettability types is given in Table 1 [20].

Table 1. Wettability classification in the function of contact [20].

\begin{tabular}{c|c} 
Contact angle $\left(^{\circ}\right)$ & Wettability \\
\hline $0-30$ & Strongly-water wet \\
\hline $30-90$ & Water-wet \\
\hline 90 & Neutral wet \\
\hline $90-150$ & Preferentially oil-wet \\
\hline $150-180$ & Strongly oil-wet
\end{tabular}

Khishvand et al. performed flooding tests over the sandstone cores, and they observed that at a pressure of $1000 \mathrm{psi}$ and temperature of $60^{\circ} \mathrm{C}$, the reservoir rock wettability in the presence of smart water had changed from oil-wet to water-wet. However, high-salinity water injection has not significantly altered the wettability of the samples [21]. Therefore, the reservoir rock's wettability by low salinity water injection leads to more water wetting and increased oil recovery [22-25].

In the case of incompatibility with the combination of injected saltwater (smart water) and the reservoir fluids, sediments caused by the reaction between them are created in the reservoir environment, which affects the recovery efficiency and fluid flow. Therefore, smart water composition should be considered before injection into the reservoir in terms of compatibility with reservoir fluids [26]. 
In loose sandstone reservoirs, any change in the composition of the injected fluid, changes in the reservoir environment's $\mathrm{pH}$, and the rock surface's wettability alteration leads to instability of the rock surface particles and causes sand production. In this process, the cement in the rock texture gradually dissolves over time due to water flow, resulting in the separation and movement of sand particles. The resulting sediments and sand particles can be blocked in the reservoir, causing some of the fluid pathways, affecting the reservoir permeability and fluid movement. Due to the high fluid flow with a high rate in the near-wellbore, sand production is more common than other points [27-29].

With the separation of sand particles and other particles from the rock surface, the reservoir's wettability can also change. This issue is very important in the enhanced oil recovery (EOR) of reservoirs [30].

Different methods can be used to prevent sand production, classified into two categories of mechanical and chemical methods. The mechanical methods are using gravel pack, slotted liner, wire wrapped screen, and pre-packed screen. Chemical methods, including the use of the warm air injection technique, silicon halide injection in the form of gas or solution, polymer injection, and resin injection, can be pointed out. These methods are usually uneconomical and sometimes reduce permeability (damage to the formation) and production [31-35].

Nanotechnology is one of the most effective chemical methods for sand production prevention. These particles have nanometer dimensions and are present in aqueous solutions in the form of charged particles, having both water-wetting and oil-wetting properties. On the one hand, while entering the reservoir environment, nanoparticles are absorbed onto the rock surface, and wettability alteration towards water wetting and reducing the interfacial tension (IFT) of water and oil, which increase production. On the other hand, by coating the rock cement's surface, it prevents its contact with the aqueous solution and, as a result, dissolves it, and therefore acts as a stabilizer and prevents sand production [36-41].

Due to their very small size, the high proportion of the area to volume of nanoparticles has very high reactivity. For the first time in 2008 , Huang et al. used nanoparticles to stabilize formation particles in a hydraulic fracturing test. Previous research showed that the use of nanoparticles could prevent the migration of minerals separated from the rock surface due to disturbing the ionic balance in the porous media [42, 43].

Yuan et al. designed experimental smart water and nanoparticles to increase oil recovery. They examined their experiments in the simultaneous injection of nanoparticles with smart water and nanofluid injection before smart water injection as a pre-flush fluid in the porous media. In the case of simultaneous injection of nanoparticles with smart water, the nanoparticles adhere to the formation particles and reduce their surface charge, causing the formation particles to adhere to the porous media wall. When nano is injected with the preflush fluid into the porous media, absorption of formation particles into the porous media becomes more effective in the migration of sand particles [44].

To prevent the production of formation particles by nanoparticles, Ogolo et al. found that, in addition to a considerable decrease in formation particles' production due to using nanoparticles, increasing the step-by-step injection rate yields better nanoparticle performance in preventing the production of formation particles [45].

Hasannejad et al. used silica oxide $\left(\mathrm{SiO}_{2}\right)$ to control the production of formation particles. Using core flooding tests and injecting silica oxide as a stabilizer for formation particles, they found that the nanoparticle could reduce the formation particles production by 80 percent at a concentration of 0.1 percent mass. Also, they measured the atomic force 
microscopy (AFM) and analyzed the results. It was observed that injecting silica nano-oxide increased the surface roughness, which they considered the most important mechanism in preventing the movement of formation particles [46].

In this paper, the effect of wettability alteration on the amount of sand production in the presence of smart water and smart nanofluids has been evaluated by conducting a large number of laboratory tests. Wettability alteration of the sandstone surface to water wetting with smart water disturbs the equilibrium on the rock surface and causes sand production. In addition to accelerating wettability alteration to water wetting, tests currently performed in the presence of smart nanofluid (Smart water $+2000 \mathrm{ppmSiO}_{2}$ ) have reduced sand production. This shows the improvement and economy of this fluid for injection into sandstone reservoirs for EOR processes.

\section{Experimental Procedures}

\subsection{Materials.}

\subsubsection{Minerals (artificial cores and thin sections).}

The unconsolidated artificial sandstone cores, which initially had sand production potential, were made with optimum composition to investigate the sand production. The artificial core is the core of the cement compound because, in addition to sand production, the made cores should resist the applied pressures. The core is composed of water, sand, cement, and kaolinite. Using kaolinite clay mineral has a shallow effect on reducing the porous media's permeability compared to other clay minerals. The combination of X-Ray Fluorescence (XRF), elemental analysis of cement and sand is given in Table 2.

Table 2. Mineralogy of sand from X-ray Fluorescence (XRF) measurements.

\begin{tabular}{c|c|c|c|c|c|c|c|c|c|c|c|c|c|c} 
Component & $\mathrm{SiO}_{2}$ & $\mathrm{Al}_{2} \mathrm{O}_{3}$ & $\mathrm{BaO}$ & $\mathrm{CaO}$ & $\mathrm{Fe}_{2} \mathrm{O}_{3}$ & $\mathrm{~K}_{2} \mathrm{O}$ & $\mathrm{MgO}$ & $\mathrm{MnO}$ & $\mathrm{Na}_{2} \mathrm{O}$ & $\mathrm{P}_{2} \mathrm{O}_{5}$ & $\mathrm{SO}_{3}$ & $\mathrm{TiO}_{2}$ & $\mathrm{LOI}$ & $\mathrm{Sr}$ \\
\hline Sand(\%) & 78.81 & 8.95 & 0.05 & 2.42 & 0.55 & 3.16 & 0.21 & - & 1.74 & - & 1.47 & 0.05 & 2.58 & - \\
\hline Cement(\%) & 20.73 & 4.12 & 0.07 & 61.91 & 3.25 & 0.78 & 3.26 & 0.21 & 0.35 & 0.08 & 2.39 & 0.31 & 2.49 & 0.07
\end{tabular}

From the artificial cores, thin sections with about $3 \mathrm{~mm}$ thickness and about $25 \mathrm{~mm}$ in diameter were cut using a cutting machine, as shown in Figure 1. The thin sections taken from the cores by a helium porosimeter and gas permeameter have an average porosity of $28.22 \%$ and average permeability of $34.31 \mathrm{md}$.

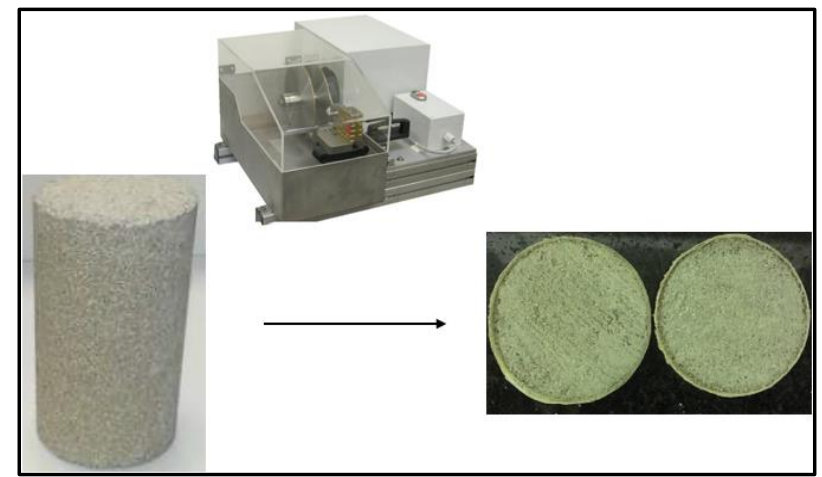

Figure 1. Sandstone core and a thin section for sand production test.

\subsubsection{Brines.}

To obtain the optimal combination of smart water, the formation water (the composition of one of the sandstone reservoirs of southern Iran) and seawater (Persian Gulf water 
composition) were initially synthesized in the laboratory by distilled water and laboratory salts (Merck). The distilled water used in the experiments is a one-time distillation type and has the characteristics of total organic contact (T.O.C < 5) and resistivity $18.2 \mathrm{M} \Omega \mathrm{cm}$. Initially, to reduce seawater's salinity, the dilution process was diluted at five ratios of 2, 5, 10, 15, and 20 times compared to its original composition. For seawater's compatibility in different proportions with formation water, the compatibility test was performed with a ratio of 50 to 50 at reservoir temperature $\left(65^{\circ} \mathrm{C}\right)$. Water 10 times diluted, which had the lowest sediment and highest compatibility with the formation water, was selected as the base water for the final compatibility test and to obtain the optimal smart water combination.

For optimization of smart water composition, Taguchi design was carried out using Minitab software. After compatibility testing of 9 smart water compositions with formation water, a combination of number 9 was selected due to less deposition as optimum smart water composition. Taguchi design in Table 3 shows that numbers 1 to 3 represent the three variables' three levels. The numbers 1, 2, and 3 represent half the initial concentration, the concentration equal to the initial concentration, and one-half of the initial concentration.

Table 3. Taguchi's algorithm.

\begin{tabular}{c|c|c|c} 
& \multicolumn{3}{|c}{ The level of variables } \\
\hline Composition number & $\mathbf{A} \rightarrow \mathbf{N a 2} \mathbf{S O}_{4}$ & $\mathbf{B} \rightarrow \mathbf{M g C l} \mathbf{2}$ & $\mathbf{C} \rightarrow \mathbf{C a C l}_{\mathbf{2}}$ \\
\hline 1 & 1 & 1 & 1 \\
\hline 2 & 1 & 2 & 2 \\
\hline 3 & 1 & 3 & 2 \\
\hline 4 & 2 & 1 & 3 \\
\hline 5 & 2 & 2 & 1 \\
\hline 6 & 2 & 3 & 3 \\
\hline 7 & 3 & 1 & 1 \\
\hline 8 & 3 & 2 & 2
\end{tabular}

The composition of optimum smart water (SW) and formation water and seawater are given in Table 4.

Table 4. Composition of formation water, seawater, and smart water.

\begin{tabular}{c|c|c|c|c|c}
\multirow{2}{*}{ Component } & $\begin{array}{c}\text { Formation } \\
\text { water } \\
\text { weight(g/l) }\end{array}$ & $\begin{array}{c}\text { Seawater } \\
\text { weight(g/l) }\end{array}$ & $\begin{array}{c}\text { Diluted } \\
\text { seawater } \\
(\mathbf{g} / \mathbf{l})\end{array}$ & $\begin{array}{c}\text { Smart water } \\
\text { weight(g/l) }\end{array}$ & Manufacturer \\
\hline $\mathrm{NaCl}$ & 150 & 28 & 2.8 & 3.364 & Merck \\
\hline $\mathrm{KCl}$ & 0 & 0.8 & 0.08 & 0.08 & Merck \\
\hline $\mathrm{CaCl}_{2} \cdot 2 \mathrm{H}_{2} \mathrm{O}$ & 49.5 & 1.38 & 0.138 & 0.069 & Merck \\
\hline $\mathrm{MgCl}_{2} \cdot 6 \mathrm{H}_{2} \mathrm{O}$ & 14.5 & 5.5 & 0.55 & 0.275 & Merck \\
\hline $\mathrm{NaHCO}_{3}$ & 0.66 & 0.1 & 0.01 & 0.01 & Merck \\
\hline $\mathrm{Na}_{2} \mathrm{SO}_{4}$ & 0.403 & 4.4 & 0.44 & 0.22 & Merck
\end{tabular}

\subsubsection{Other materials.}

In this experiment, nano-silica $\left(\mathrm{SiO}_{2}\right)$ was used to prepare smart Nanofluids (smart water + nanoparticles). The Nano $\mathrm{SiO}_{2}$ used has a purity of more than $99 \%$, the average particle size is about 20 to $30 \mathrm{~nm}$, and has a specific surface area of about 200 to $600 \mathrm{~m}^{2} / \mathrm{g}$. For oil wetting thin sections, a combination of stearic acid (fatty acid) $\mathrm{CH}_{3}\left(\mathrm{CH}_{2}\right)_{2} \mathrm{COOH}$ (molecular weight $284.48 \mathrm{~g} / \mathrm{mol}$ and density $0.941 \mathrm{~g} / \mathrm{ml}$ ) and normal heptane $\mathrm{C}_{7} \mathrm{H}_{16}$ (molecular weight $100.21 \mathrm{~g} / \mathrm{mol}$ and density $0.684 \mathrm{~g} / \mathrm{ml}$ ) were used. Kerosene oil ( $45.5^{\circ} \mathrm{API}$ and $1.5 \mathrm{cp}$ viscosity) was used for the contact angle test. 


\subsection{Methods.}

\subsubsection{Nanofluid preparation.}

By obtaining the optimum smart water composition, $\mathrm{SiO}_{2}$ nanoparticles were added to the smart water in two concentrations of 1000 and 2000 ppm to determine the most stable and optimal concentration in the tank conditions. The reason for using these two concentrations is that, essentially, the high concentrations of nanofluids are not economically efficient, and the high concentrations of nano are not used due to lack of stability [47]. By adding nanoparticles of $\mathrm{SiO}_{2}$ at specific concentrations to smart water for the initial dispersion of nanoparticles, we place the fluid on a magnetic stirrer for $30 \mathrm{~min}$ (at a rotation speed of about $1800 \mathrm{rpm}$ ). To uniformly disperse the nanoparticles in the fluid for 1 hour, we place them in an ultrasonic bath (with a frequency of $24 \mathrm{kHz}$ and a power of $400 \mathrm{~W}$ ). The creation of the wave disperses the nanoparticles evenly in the solution and allows the investigation of stability or instability over time and under temperature conditions [48]. The nanofluid preparation steps are shown in Figure 2.

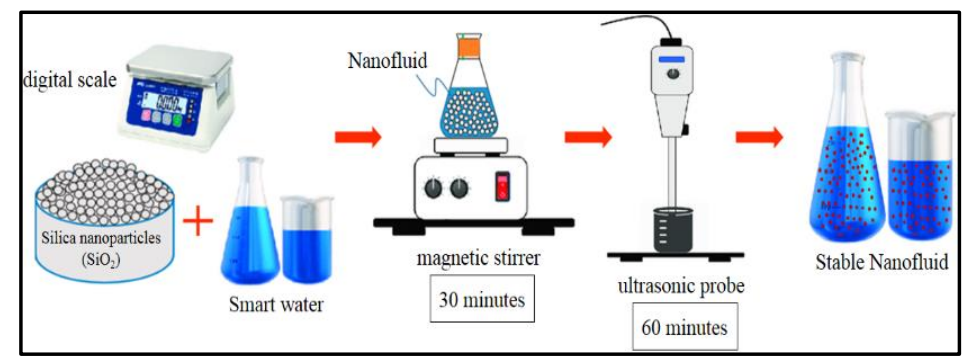

Figure 2. Schematic of smart nanofluid preparation steps in this study.

The manufactured nanofluids were placed in the oven at reservoir temperature $\left(65^{\circ} \mathrm{C}\right)$ for 24 hours, and the stability was visually checked. The two main criteria for nano stability in smart water are Zeta potential and Dynamic Light Scattering (DLS). According to the isoelectric point's (IEP) definition in which the $\mathrm{pH}$ of zeta potential value is equal to 0 , the IEP value for silica nanoparticles is in the 2-3 range. By moving away from this $\mathrm{pH}$, the value of zeta potential changes and causes nanofluid stability [49]. Nanoparticles are gradually absorbed through unequal charges to form clumps that eventually lead to nanofluid instability [50]. Due to both nano concentrations' visual stability, based on the results of Zeta potential and DLS tests, which are given in Table 5 and Figure 3, nanoparticles with a concentration of $2000 \mathrm{ppm}$ in smart water $(\mathrm{pH}=8)$ were selected as the optimum nanofluid.

Table 5. Result of zeta potential and DLS test.

\begin{tabular}{c|c|c|c|c} 
Nano fluid & $\mathbf{p H}$ & Zeta potential $(\mathbf{m V})$ & Average diameter(nm) & Stability quality \\
\hline $\mathrm{SiO}_{2}(1000 \mathrm{ppm})$ & 8 & -21.4 & 277 & good \\
\hline $\mathrm{SiO}_{2}(2000 \mathrm{ppm})$ & 8 & -23.9 & 344 & Very good
\end{tabular}

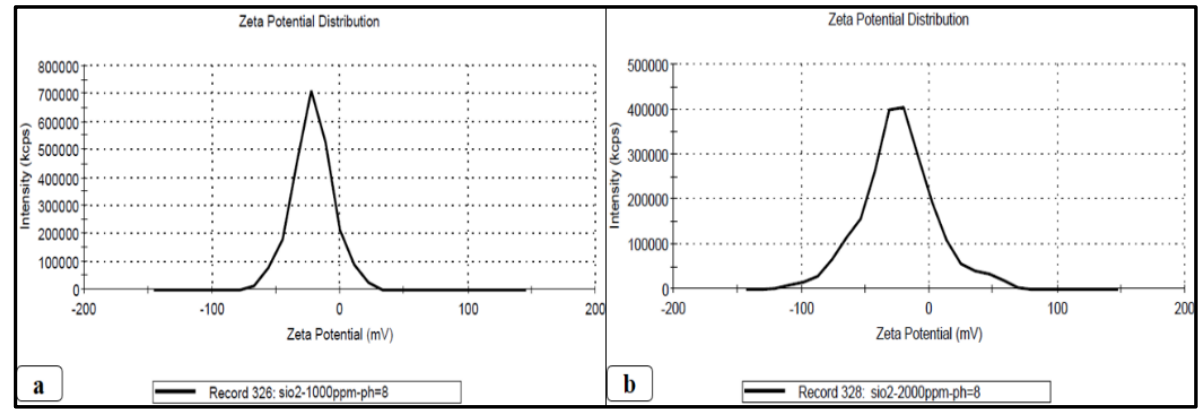

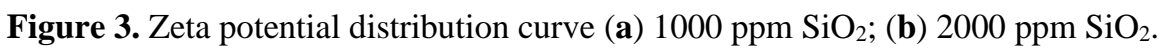




\subsubsection{Water-wet sandstone.}

Artificial cores are made because water is used in their composition, and the obtained cores are placed in water (calcite solution) for 28 days to achieve sufficient strength. The core is initially thoroughly water wet. The contact angle of the water-wet base thin section in the presence of kerosene oil is 56.702 degrees. Also, to investigate the effect of the contact angle of water-wet sandstone, the thin base section was placed in distilled water $(\mathrm{pH}=7$ (neutral $\mathrm{pH})$ ) for 72 hours. Its contact angle was obtained at 49.883 degrees in the presence of kerosene oil. Distilled water does not react with rock due to its neutral $\mathrm{pH}$ and lack of ions, so sand production does not occur. Figure 4 shows the contact angle of the base and $72 \mathrm{hr}$. in distilled water-thin sections.

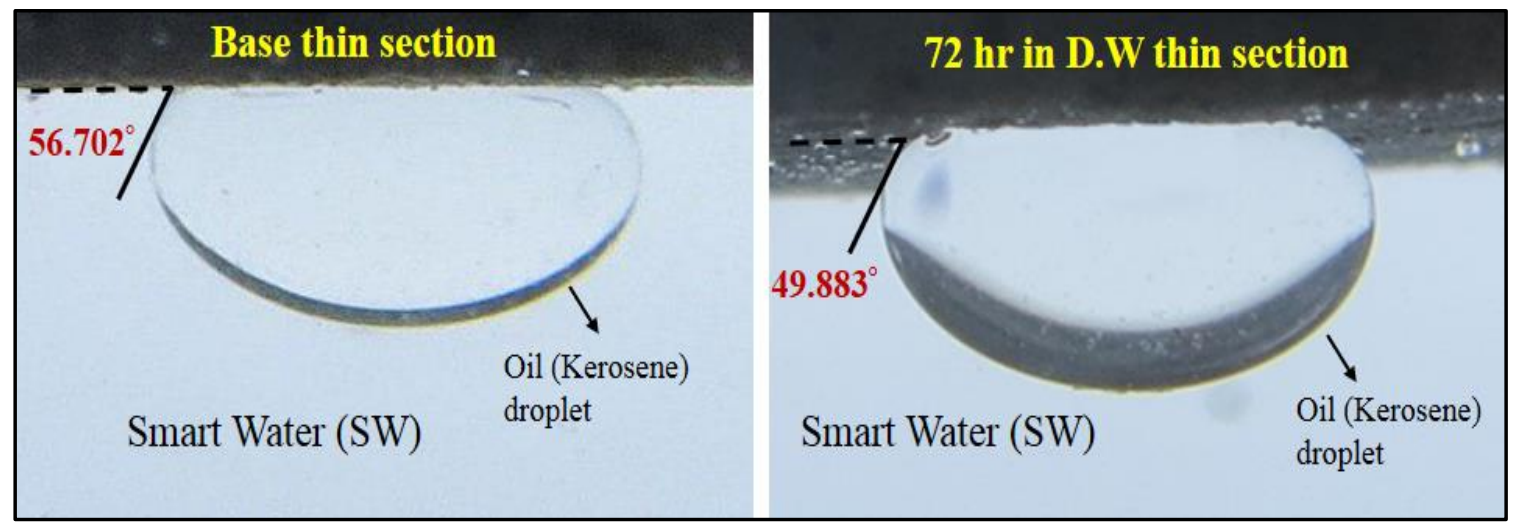

Figure 4. Contact angle of water wet (WW) thin sections.

2.2.3. Oil wetting and neutral wetting procedure.

Model oil was used for wettability alteration of thin sections towards oil wetting. The oil model consists of a combination of stearic acid and normal heptane. Stearic acid (fatty acid) has a polar head and a non-polar head that adheres to the rock surface from the polar head. Their non-polar head can be dissolved in alkanes. In this case, London forces are the cause of the interconnection of fatty acid and oil molecules. Stearic acid can dissolve in normal heptane and heavier alkanes [51, 52].

To investigate the effect of different contact angles, the rock was oil wetted at two concentrations of 0.01 and 0.03 molar stearic acid in normal heptane. Thin sections were placed in a solution of acetic acid and normal heptane at $65^{\circ} \mathrm{C}$ in an oven (reservoir temperature) for 72 hours. Figure 5 shows solutions of 0.01 and 0.03 molar stearic acid in normal heptane and shows the thin sections within the solution. Also, by placing the rock at 0.005 molar of stearic acid and normal heptane solution similar to the two concentrations mentioned, the contact angle that the rock finds is equal to 92.121 degrees, which is almost neutral-wet, according to Table 1 .

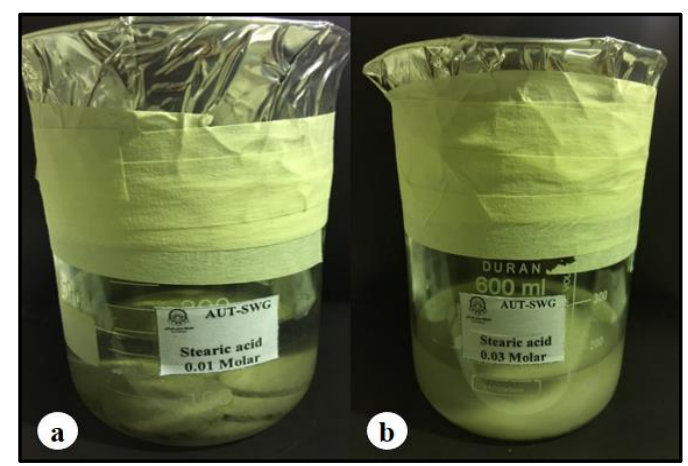

Figure 5. (a) 0.01 ; (b) 0.03 molar stearic acid in normal heptane. 


\subsubsection{Contact angle measurement.}

To investigate the effect of smart water and smart nanofluid (2000 $\mathrm{ppm} \mathrm{SiO}_{2}$ in smart water) on changes of contact angle and sand production, each of the thin sections of water-wet and oil-wet with concentrations of $0.01 \mathrm{M}, 0.03 \mathrm{M}$, and the neutral-wet thin section of $0.005 \mathrm{M}$ (stearic acid + normal heptane) were placed in the beaker containing smart water and smart nanofluid. The fluid and thin section of the sample was placed in an oven at $65^{\circ} \mathrm{C}$, simulating reservoir temperature. For five days every 24 hours, the rock's contact angle was measured in the presence of smart water kerosene oil. The angle created by the denser fluid (smart water) is considered as the contact angle between the rock and oil droplet. The contact angle measurement was performed in atmospheric conditions. The schematic setup of the contact angle measurement is shown in Figure 6.

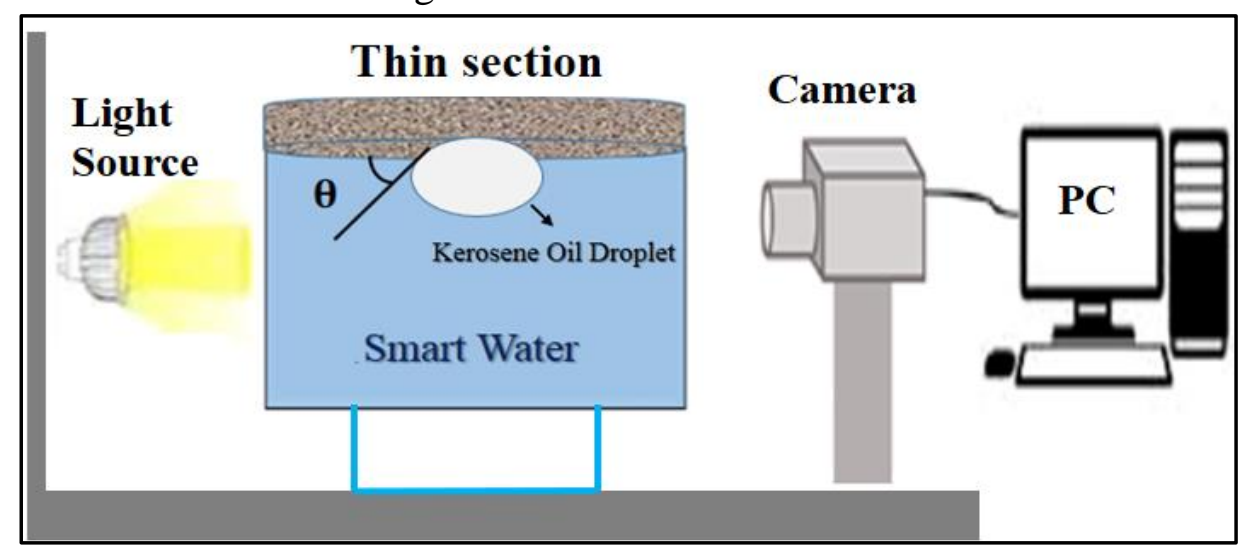

Figure 6. Contact angle apparatus schematic.

\subsubsection{Weighing of sand production.}

We first measure the weight of completely dry thin sections with a digital balance by an accuracy of $0.01 \mathrm{~g}$. Then we put one number from each thin section in our special beaker. We place the beakers in a $65^{\circ} \mathrm{C}$ oven, the reservoir temperature. After 24 hours, we take out the thin section with high accuracy and sensitivity from the fluid of smart water and smart nanofluid and put it in an oven with the same temperature of $65^{\circ} \mathrm{C}$ for 2 hours until it dries completely. Then we weigh each of the thin sections. We transfer the thin sections to our specific beaker, place them in an oven at $65^{\circ} \mathrm{C}$ and repeat this process for five days $(120 \mathrm{hr}$.) every 24 hours.

\section{Results and Discussion}

\subsection{Wettability alteration effect on sand production in smart water.}

One of the main active mechanisms of smart water for increasing reservoirs' oil production is the wettability alteration toward water-wet conditions [53, 55]. This wettability alteration is caused by disturbing the equilibrium conditions of the ions in the reservoir environment. For this purpose, it is possible to use different ions such as $\mathrm{Ca}^{2+}, \mathrm{Mg}^{2+}$, and $\mathrm{SO}_{4}{ }^{2-}$ in the composition of the injected water to the reservoir with low salinity and create changes in the ionic power of the injected water [56]. The competition between disjoining pressure, capillary pressure, and removal of naphthenic acids from the rock surface define the ultimate wettability after smart water injection in the IOR process. By altering the electrostatic repulsive force and removing naphthenic acids using the ion exchange mechanism, smart water alters the 
disjoining pressure at the rock surface and the wettability alteration towards more water wetting $[57,58]$.

Due to the contact of smart water with cement and clay minerals of the rock surface, the rock cement and clay minerals are gradually separated from the surface rock. Thus, the rock's surface charges have changed, and polar and charged particles in the oil cannot remain on the rock surface. Therefore, the wettability of the reservoir rock moves towards more waterwet conditions [56, 59].

Two layers can be considered surrounding the rock. The first layer is called the stern layer and only includes single and double capacity cations such as $\mathrm{Na}^{+}, \mathrm{Ca}^{2+}$, and $\mathrm{Mg}^{2+}$. It is absorbed in the rock due to chemical interactions, while the second layer, known as the diffuse layer, can have particles of negative charge within itself. If particles with negative charge can be absorbed into the stern layer cations, the stone has an oil wetting property.

Suppose the stern layer's cations can absorb particles with a negative charge of oil. In that case, they give the rock surface an oil wetting property. By reducing the injectable water's salinity, the ionic strength decreases. The diffuse layer gradually thickens, resulting in a lower chance of negatively charged particles being absorbed into the stern layer's cations. During this process, non-complex cations have replaced organic and organic-metallic compounds, and wettability has approached more water wetting, leading to increased oil recovery [60, 61].

Recently, smart water injections in sandstone reservoirs cause sand production and migration of formation particles. In these experiments, we investigated the effect of wettability alteration on sand production in sandstone reservoirs.

Table 6. Initial weight of thin section in smart water.

\begin{tabular}{c|c|c|c|c|c}
$\begin{array}{c}\text { Type of thin } \\
\text { section }\end{array}$ & $\begin{array}{c}72 \mathrm{hr} \text {. in Distilled } \\
\text { water (water wet) }\end{array}$ & $\begin{array}{c}\text { Base sandstone } \\
\text { (water wet) }\end{array}$ & $\begin{array}{c}0.005 \mathrm{M} \text { (Neutral } \\
\text { wet) }\end{array}$ & $\begin{array}{c}0.01 \mathrm{M} \text { (oil- } \\
\text { wet) }\end{array}$ & $\begin{array}{c}0.03 \mathrm{M} \text { (oil- } \\
\text { wet) }\end{array}$ \\
\hline Weight(g) & 7.82 & 5.56 & 6.13 & 8.14 & 6.05
\end{tabular}

Initially, 50cc of optimum smart water (the composition of Table 4) was poured into a beaker. Thin sections with different wettability, the dry weight is given in Table 6 , were placed in a beaker containing smart water. We placed them at a reservoir temperature of $65^{\circ} \mathrm{C}$ in the oven and checked the contact angle and sand production every 24 hours.

As shown in Figure 7, the maximum amount of sand production from the rock is observed in the first 24 hours. The amount of sand production decreases over time. Stress caused by wettability alteration of the rock in the presence of smart water and electrostatic force changes disturbs the equilibrium on the rock surface. It causes the sand to separate from the rock surface. Over time, wettability alteration (contact angle alters) decreases, and sand production is gradually reduced. Due to low salinity water contact with the mineral of rock surface and cement between the loose sandstone particles, the ionic balance of the environment is disturbed. As a result, the process of leaching and separation of sand particles from the rock surface occurs. Over time, as the stress on the rock surface stabilizes, sand production decreases.

In this study, water-wet, neutral-wet, and oil-wet effects have been observed. The base contact angle in the presence of smart water fluid has been taken from thin sections every 24 hours. According to Table (7), the contact angle of thin sections of $72 \mathrm{hrs}$ in distilled water and base sandstone is completely water-wet. Thin sections of $0.01 \mathrm{M}$ and $0.03 \mathrm{M}$ (stearic acid $+\mathrm{n}$ heptane) are completely oil-wet, and the thin section of $0.005 \mathrm{M}$ is close to neutral-wet. 
Table 7. Base contact angle.

\begin{tabular}{c|c|c|c|c|c}
$\begin{array}{c}\text { Type of thin } \\
\text { section }\end{array}$ & $\begin{array}{c}72 \mathrm{hr} \text {. in Distilled } \\
\text { water }\end{array}$ & Base sandstone & $0.005 \mathrm{M}$ & $0.01 \mathrm{M}$ & $0.03 \mathrm{M}$ \\
\hline $\begin{array}{c}\text { Contact } \\
\text { angle(degree) }\end{array}$ & $49.883^{\circ}(\mathrm{WW})$ & $56.702^{\circ}(\mathrm{WW})$ & $92.121^{\circ}(\mathrm{NW})$ & $120.314^{\circ}(\mathrm{OW})$ & $146.551^{\circ}(\mathrm{OW})$
\end{tabular}

According to Figure 7, the highest amount of sand production is related to water-wet thin sections. A thin section $72 \mathrm{hr}$. in distilled water has the highest sand production, while the weight loss of rock is $0.23 \mathrm{~g}$, and sand production is $2.941 \%$ of the total rock. Also, the water wet base thin section has sand production close to the thin section that was placed in distilled water for $72 \mathrm{hrs}$. The amount of sand produced is $0.16 \mathrm{~g}$, which is about $2.877 \%$ of the thin section's total weight. Also, the trend of decreasing the contact angle of these two water-wet thin sections is shown in Figure 8.

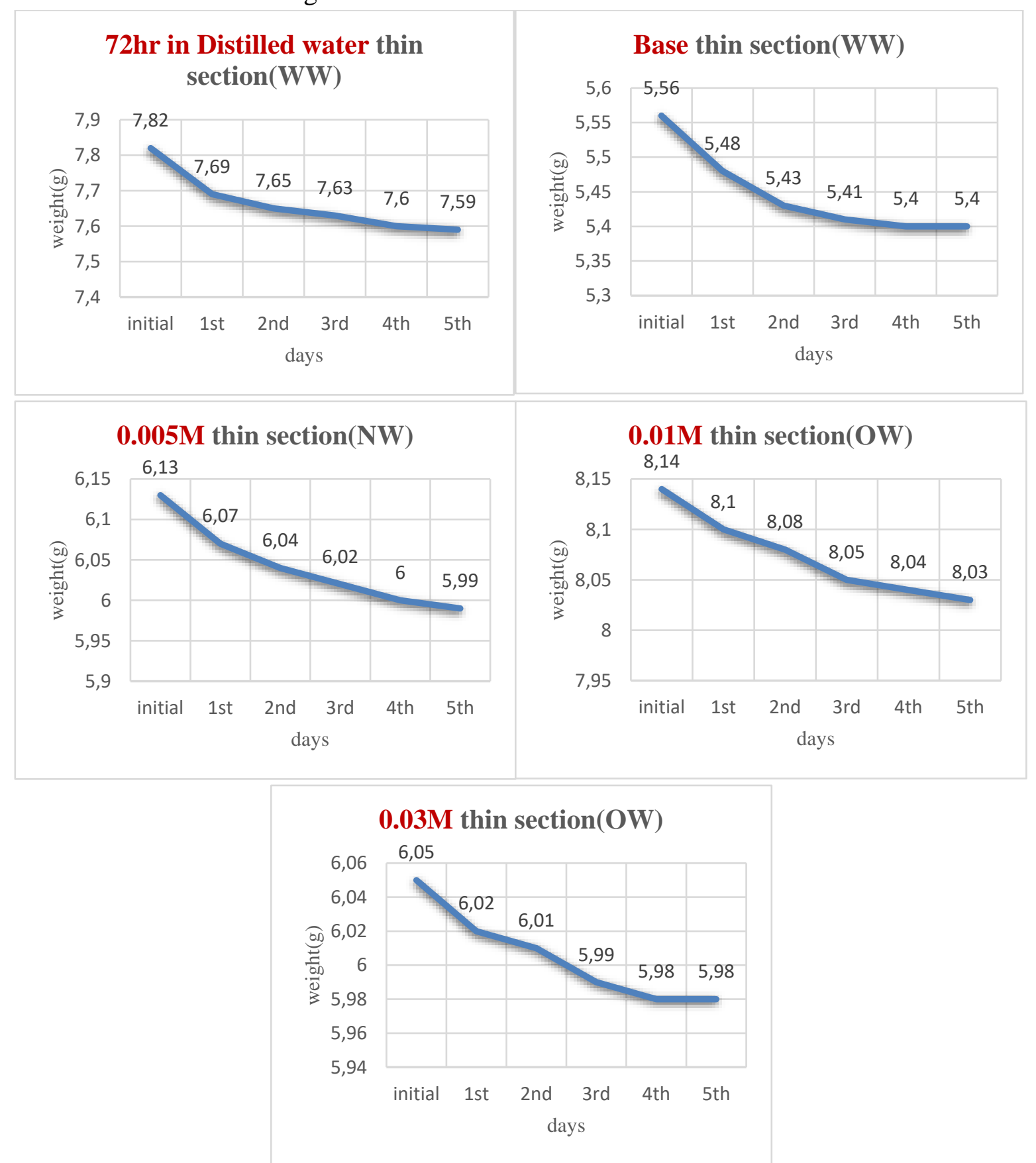

Figure 7. Sand production in smart water in different wettability. 
According to Figure 7, the maximum sand production in the $0.005 \mathrm{M}$ thin section is similar to other thin sections in the first 24 hours. The amount of sand production decreases. The sand production of the NW thin section is lower than that of WW thin sections, and the amount of sand production is $0.14 \mathrm{~g}$, which is $2.284 \%$ of the thin section's total weight. The contact angle alteration process of this thin section is shown in Figure 8.

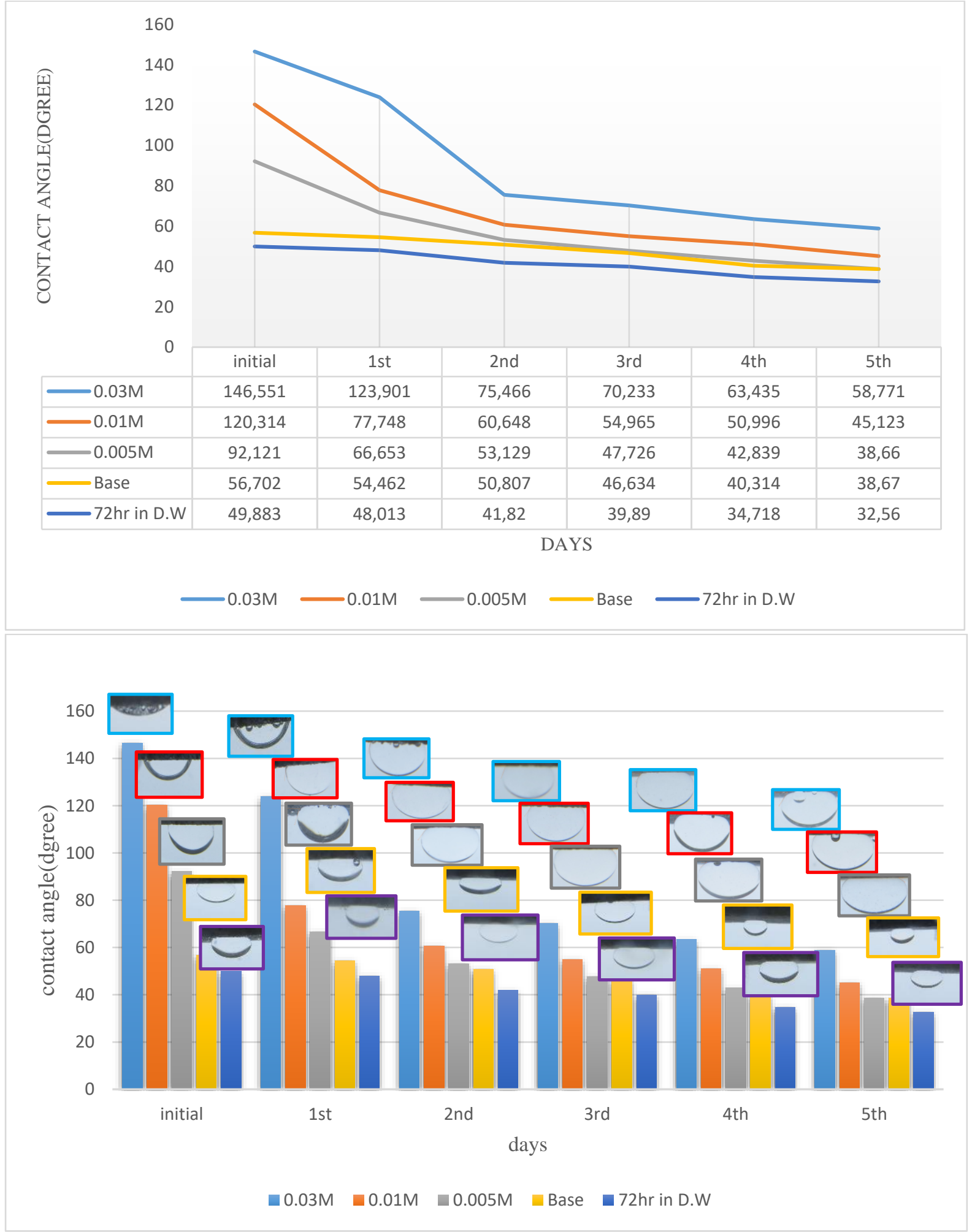

Figure 8. Contact angle measurement in smart water.

As can be seen in Figure 7, the lowest sand production is related to OW thin sections. The wettability goes towards more oil-wetting. Sand production decreases due to gradual wettability alteration towards water wetting, and the stresses and equilibrium on the rock 
surface change more slowly. Also, due to the strong molecular bonds of fatty acids (petroleum) on the surface of the oil wetting rocks and the adhesion created, less sand is produced from the rock's surface. In the $0.01 \mathrm{M}$ thin section, the amount of sand production is $0.011 \mathrm{~g}$, which is $1.351 \%$ of the total weight of the rock, and in the $0.03 \mathrm{M}$ thin section, the amount of sand production is $0.07 \mathrm{~g}$, which is $1.157 \%$ of the total weight of the rock. The trend of changes in the OW thin sections' contact angle from oil-wet toward water-wet is shown in Figure 8.

\subsection{Wettability alteration effect on sand production in smart nanofluid.}

In the process of smart water injection into the reservoir, due to the very low salinity of the injected water compared to formation water, the ionic balance in the reservoir environment is disturbed. There is an interaction between the minerals forming the rock surface. Mainly the cement between the particles and available ions occurs in the environment. As a result, the cement on the rock surface in the presence of smart water tends to separate from the rock surface. This creates a problem for separating sand particles from the rock surface and migration along with the fluid flow.

One way to prevent sand particles from migrating due to rock surface contact with low salinity water is to cover the rock surface and mostly the cement between the particles using nanoparticles. It is one of the most widely used nanoparticles in IOR silica $\left(\mathrm{SiO}_{2}\right)$ nanoparticles

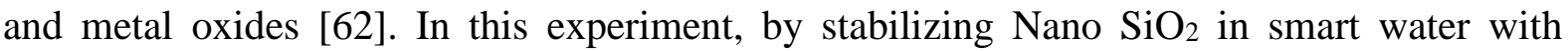
optimum concentration, in addition to increasing production caused by a faster shift to water wetting and reducing interfacial tension (IFT), it also reduces sand production [63, 65]. Based on the Zeta potential and DLS test results related to Table 5, nanofluid concentration of 2000 was selected.

To see the wettability alteration from water wetting to oil wetting by (stearic acid $+n$ heptane) and the effect of nanoparticles on the rock surface, Field Emission Scanning Electron Microscopy (FESEM) images have been taken. They show that the presence of smart nanofluid (2000 ppm $\mathrm{SiO}_{2}$ ) can completely cover the rock's surface and act as a barrier, reducing stress on the rock surface and preventing sand production. Figure 9 shows the wettability alteration from water wetting to oil wetting and rock surface before contact with the nanofluid. As you can see, there is no cover or barrier on the rock surface, and all the rock grains can be in direct contact with the smart water.

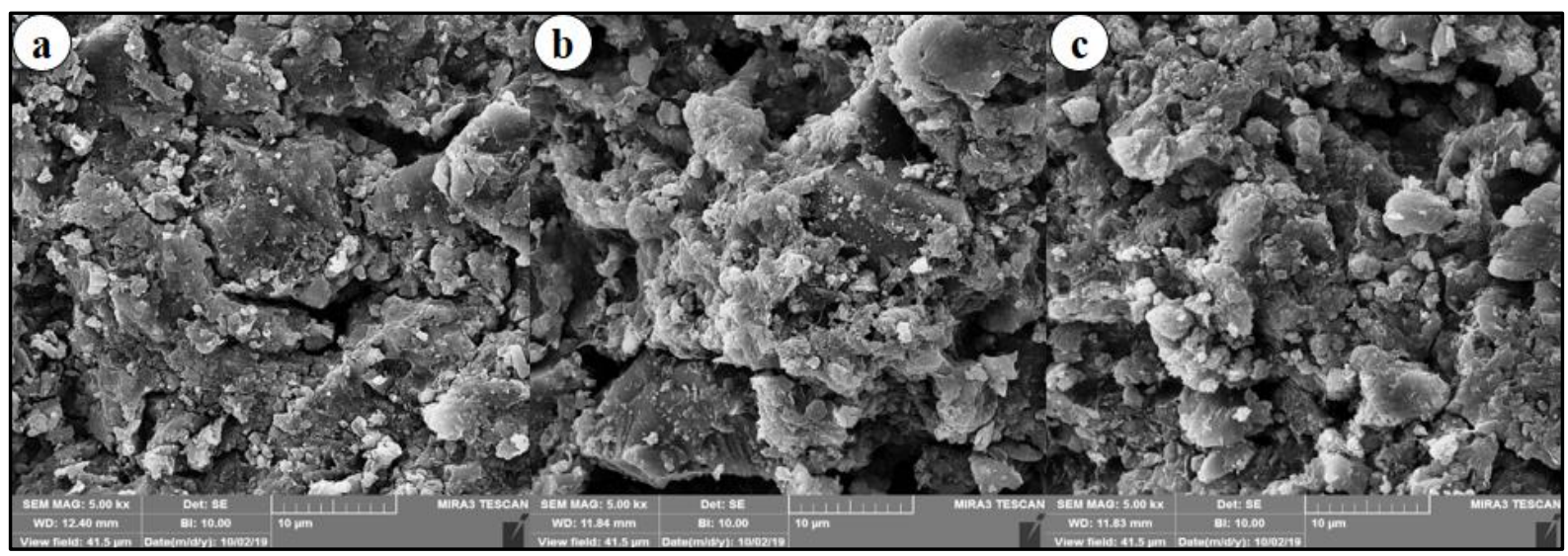

Figure 9. Rock surface before submerging in Nano fluid. (a) base (WW); (b) 0.01M (OW); (c) 0.03M (OW).

Now we put the thin section in the smart nanofluid for 24 hours. After 24 hours, the nanofluid is given a soaking time to affect the rock. The nanoparticles settle on the rock surface. 
Figure 10 shows the spherical silica nanoparticles that the rock surface has absorbed cover the rock surface like a coating. It is also helping the oil production process by reducing interfacial tension and improving the wettability alteration towards more water-wet conditions. It prevents smart water contact with rock cement and thus leaching the rock, leading to preventing sand production.

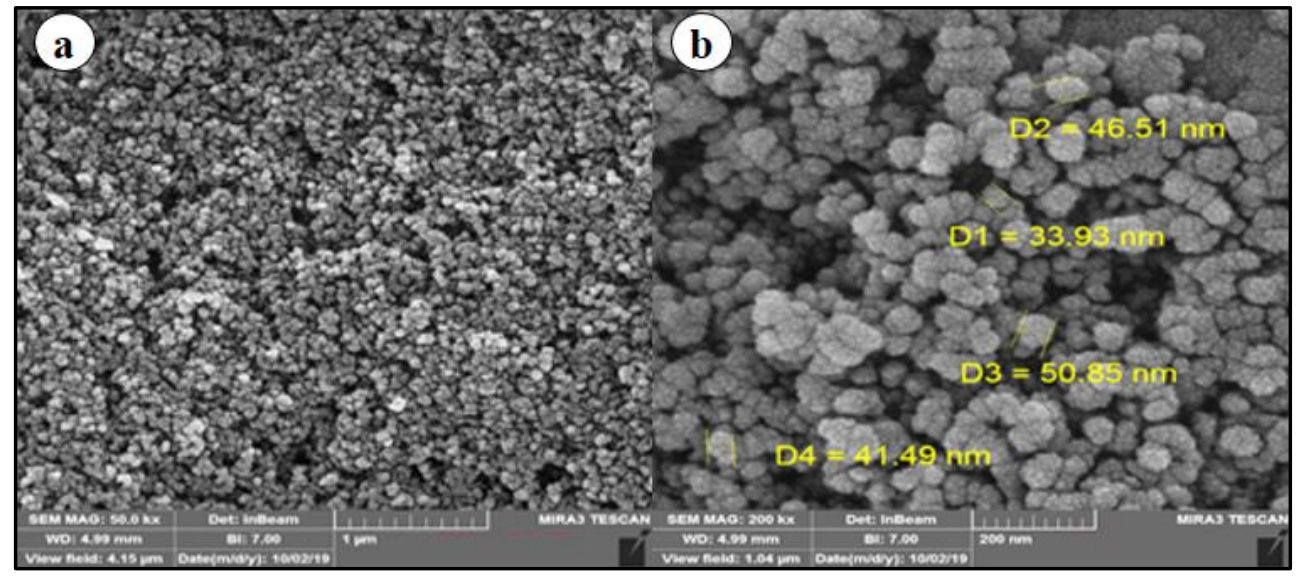

Figure 10. rock surface after submerging in a smart nanofluid. (a) surface absorption of nanoparticles on rock surface; (b) particle size absorbed on the rock surface.

The pressure applied to the solid surface in the face of the fluid adhesion force, which tends to disjoin the fluid from the surface, is called the disjoining pressure. As shown in Figure 11, nanoparticles are absorbed into the rock surface during the surface adsorption process. Similar to a protective layer, nanoparticles prevent fluid from reaching the surface of the rock. On the other hand, by applying disjoining pressure to the oil phase, they separate oil droplets attached to the rock surface. As a result, the wettability of the reservoir rock leads to more water-wet conditions. This pressure is the result of Brownian forces and electrostatic repulsion between nanoparticles. The smaller the nanoparticle size and the higher the nanoparticle concentration, the higher the pressure. Nanoparticles alter disjoining pressure by structurally disjoining pressure at the wedge film. The excess pressure due to the accumulation of nanoparticles in the wedge film leads to overcoming the Van der Waals forces and changing the wettability [66-68].

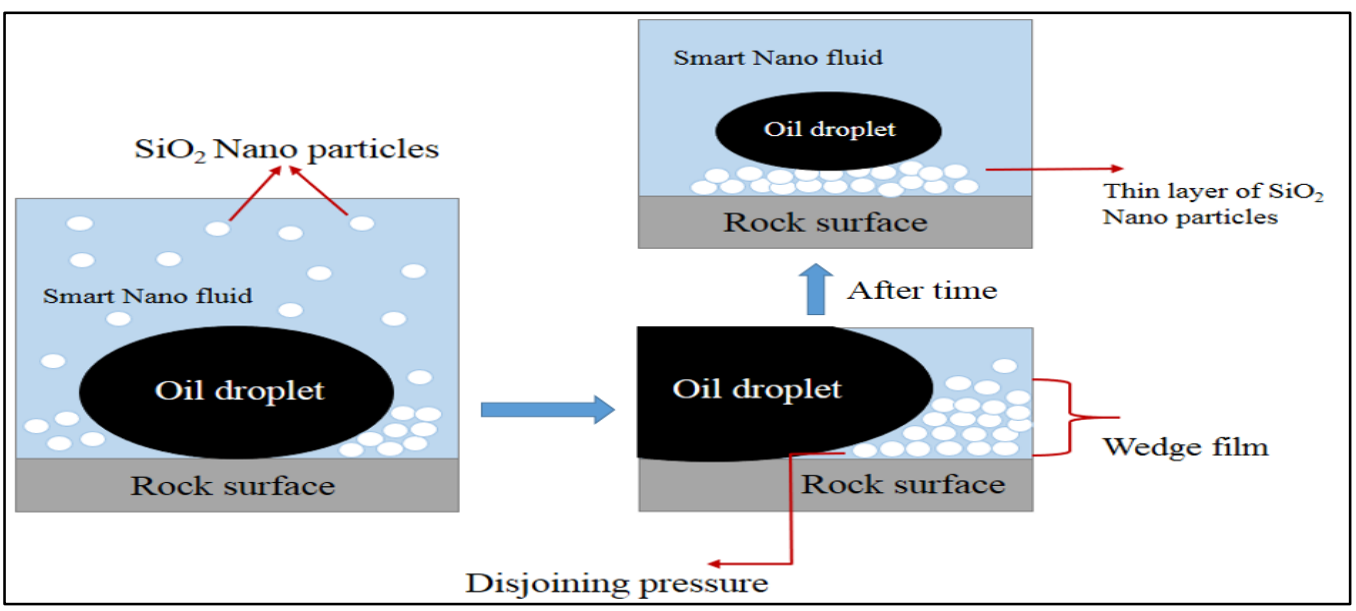

Figure 11. Process of wettability alteration by applying disjoining pressure from silica $\left(\mathrm{SiO}_{2}\right)$ nanoparticles to the oil droplets attached to the rock surface.

Nanoparticles have a very high ability for wettability alteration of the rock surface. Depending on the nature of the oil-wet or water-wet nanoparticles, the surface can become oil- 
wet or water-wet. As the silica nanofluid is absorbed into the rock surface, the surface wettability moves toward being more water-wet [69].

Similar to previous experiments, initially in smart water, the $2000 \mathrm{ppm}$ silica Nanoparticles $\left(\mathrm{SiO}_{2}\right)$ are stabilized and poured into a $50 \mathrm{cc}$ volume within its special beakers. Then, the thin sections' weight becomes completely dry, which can be seen in Table 8 . We put the thin sections in our special beaker, including the smart nanofluid, and place them in an oven with a temperature of $65^{\circ} \mathrm{C}$, which is the reservoir temperature. We investigate the sand production, and the contact angle changes every 24 hours for five days.

\begin{tabular}{c|c|c|c|c|c} 
Table 8. The initial weight of thin section in a smart nanofluid. \\
$\begin{array}{c}\text { Type of thin } \\
\text { section }\end{array}$ & $\begin{array}{c}\mathbf{7 2} \text { hr. in Distilled } \\
\text { water (water wet) }\end{array}$ & $\begin{array}{c}\text { Base sandstone } \\
\text { (water wet) }\end{array}$ & $\begin{array}{c}\mathbf{0 . 0 0 5} \mathbf{M} \\
\text { (Neutral wet) }\end{array}$ & $\mathbf{0 . 0 1} \mathbf{M}$ (oil-wet) & $\begin{array}{c}\mathbf{0 . 0 3} \mathbf{M} \\
\text { (oil-wet) }\end{array}$ \\
\hline Weight(g) & 6.34 & 7.99 & 6.83 & 6.19 & 6.94
\end{tabular}

The experiments performed in the presence of nanoparticles show that the amount of sand production is significantly reduced. After the soaking time and settlement of nanoparticles on the rock surface, sand production is almost stopped. Similar to the experiments conducted on smart water, the results of these experiments show that the lowest sand production is related to the more oil-wet thin section $(0.03 \mathrm{M})$. The highest sand production is related to the more water-wet thin section (72hr. in distilled water).

The water-wet thin sections (base and $72 \mathrm{hr}$. in distilled thin sections) had the highest sand production. According to Figure 12, the highest sand production in all thin sections is related to the first 24 hours, and after the settlement of $\mathrm{SiO}_{2}$ nanoparticles on the rock surface and creating a coating on the rock surface, the amount of sand production is greatly reduced and ultimately comes to an end.

The amount of sand production in the ( $72 \mathrm{hr}$. in distilled water) thin section is $0.15 \mathrm{~g}$, which is about $2.366 \%$ of the thin section's total weight. Also, the amount of sand production in the thin base section is 0.12 , which is $1.502 \%$ of the rock's total weight. According to Figure (12), the maximum sand production in the $0.005 \mathrm{M}$ thin section is similar to other thin sections in the first 24 hours. The amount of sand production decreases. The sand production of the NW thin section is lower than the WW thin sections, and the amount of sand production is $0.09 \mathrm{~g}$, which is $1.317 \%$ of the thin section's total weight.

According to Figure 12 and the factors mentioned, the lowest amount of sand production is related to oil-wet thin sections. The amount of sand production in the $0.01 \mathrm{M}$ thin section is $0.07 \mathrm{~g}$, which is $0.987 \%$ of the total weight of the thin section, and in the $0.03 \mathrm{M}$ thin section, which has the lowest amount of sand production is $0.02 \mathrm{~g}$, which is $0.288 \%$ of the total weight of the thin section. In the $0.03 \mathrm{M}$ thin section, the amount of sand production from the second day is completely stopped.

According to Figure 13, as expected, a decrease in contact angle occurred faster in all wettability than in smart water without nano, which indicates a fluid improvement.

According to Figure (12) and the factors mentioned, the lowest amount of sand production is related to oil-wet thin sections. The amount of sand production in the $0.01 \mathrm{M}$ thin section is $0.07 \mathrm{~g}$, which is $0.987 \%$ of the total weight of the thin section, and in the $0.03 \mathrm{M}$ thin section, which has the lowest amount of sand production is $0.02 \mathrm{~g}$, which is $0.288 \%$ of the total weight of the thin section. In the $0.03 \mathrm{M}$ thin section, the amount of sand production from the second day is completely stopped. 


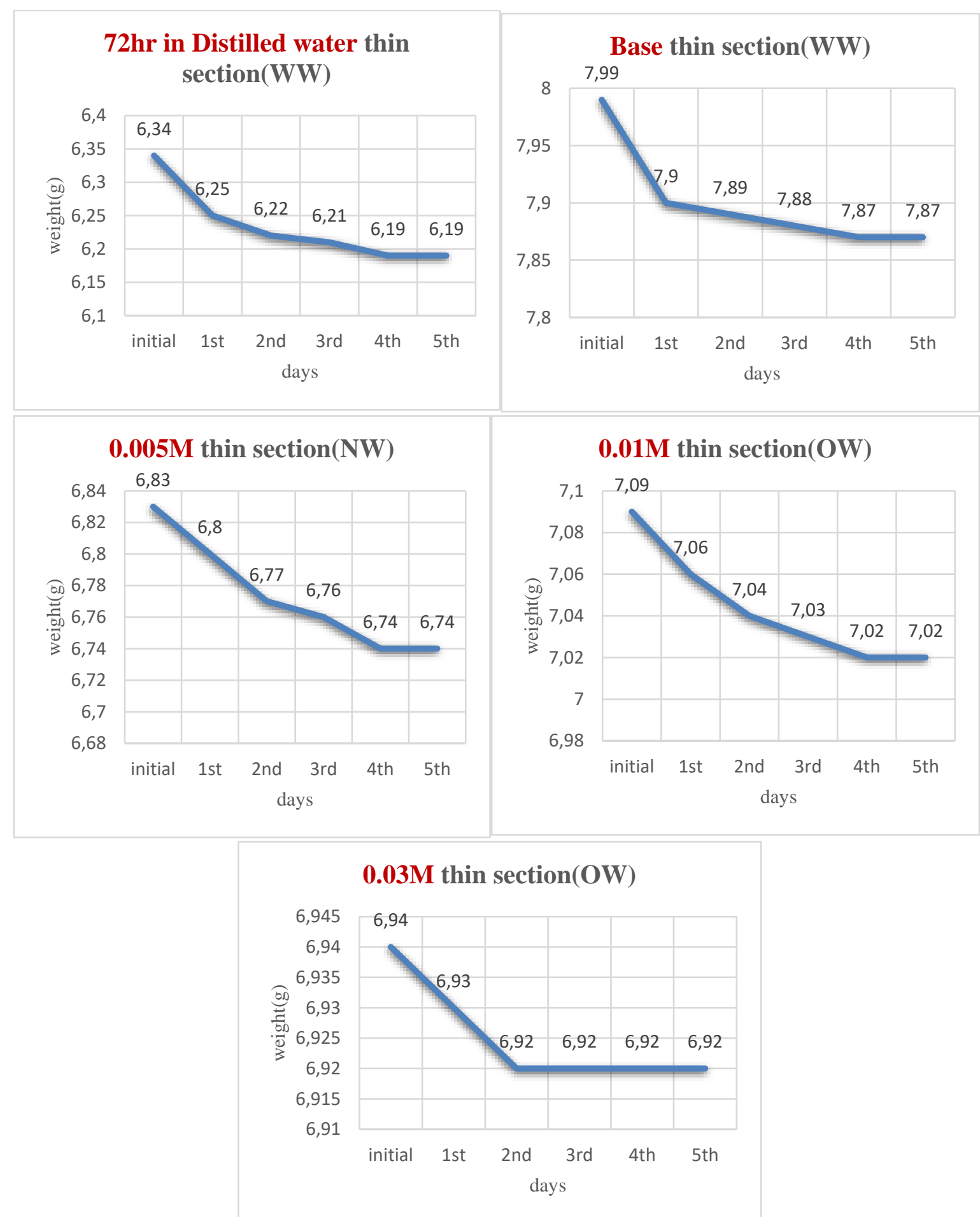

Figure 12. Sand production in smart water with nano (Smart Nanofluid) in different wettability.

According to Figure 13, as expected, a decrease in contact angle occurred faster in all wettability than in smart water without nano, which indicates a fluid improvement.

According to the results, as much as the sandstone has strong oil wetting, a smaller amount of sand is produced. Based on the experiment results, it was observed that smart water with nanoparticles significantly reduces sand production, and after a while, the amount of sand production comes to an end. A comparison between the percentage of sand produced by different types of thin sections during five days in the presence of smart water and smart nanofluid is given in Figure (14). 


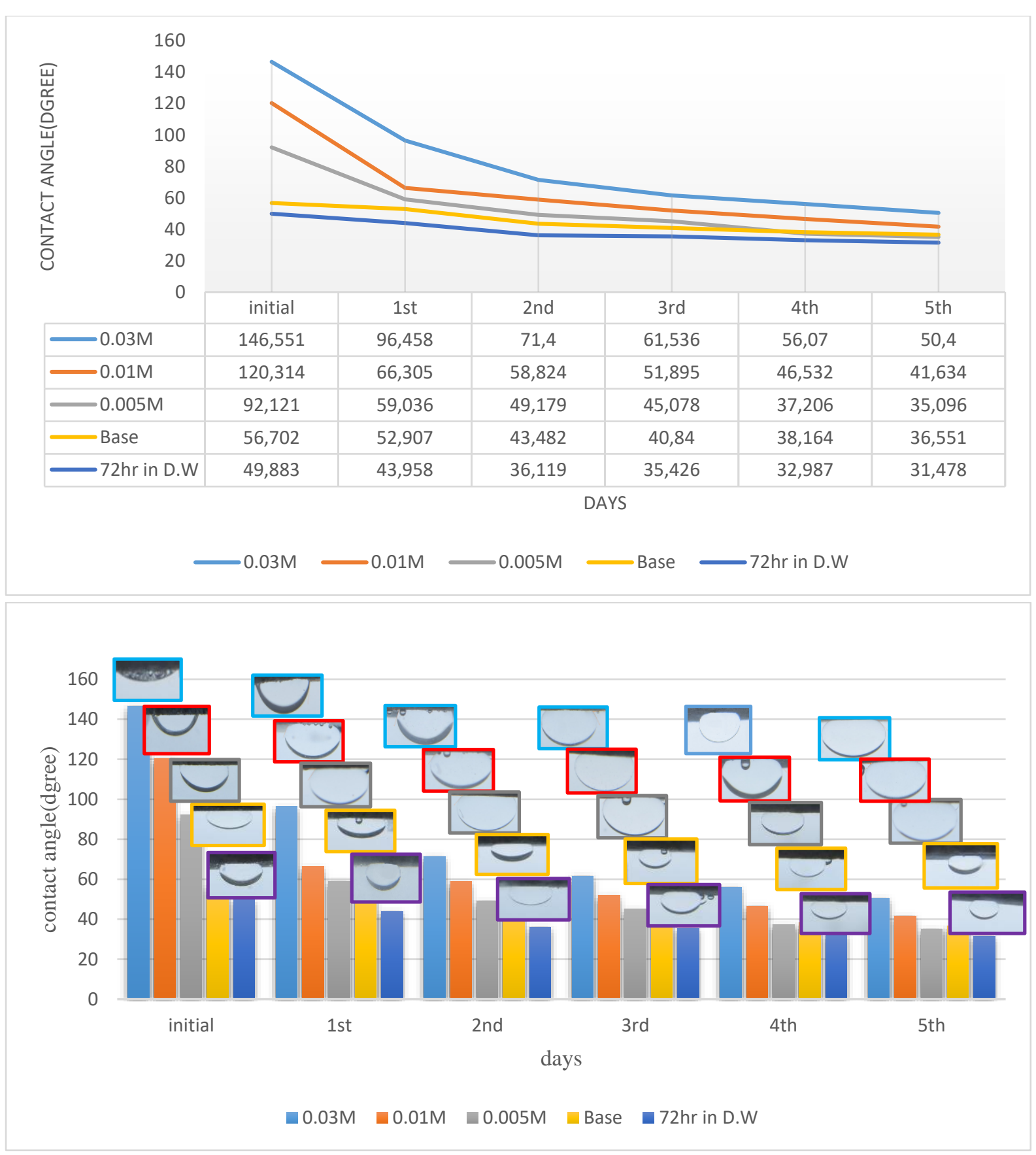

Figure 13. Contact angle measurement in smart water (smart nanofluid effect).

\section{Conclusions}

With smart water injection into unconsolidated sandstone reservoirs, the competition between disjoining pressure and capillary pressure and removing naphthenic acids result in wettability alteration of the rock surface to water-wet conditions. Wettability alteration of the unconsolidated sandstone surface is one of the main factors disturbing the equilibrium in the rock surface and sand production.

Enhanced oil recovery processes, such as smart water injections, usually take place in reservoirs where the natural production life is over. Most of these reservoirs have oil-wet conditions because of the asphaltene deposition and adhesion of oil droplets on the rock surface. Due to the strong bonding of oil molecules (fatty acids) with the rock surface, the $0.01 \mathrm{M}$ and $0.03 \mathrm{M}$ (stearic acid $+\mathrm{n}$-Heptane) thin sections had lower sand production in the presence of smart water and smart nanofluids. 


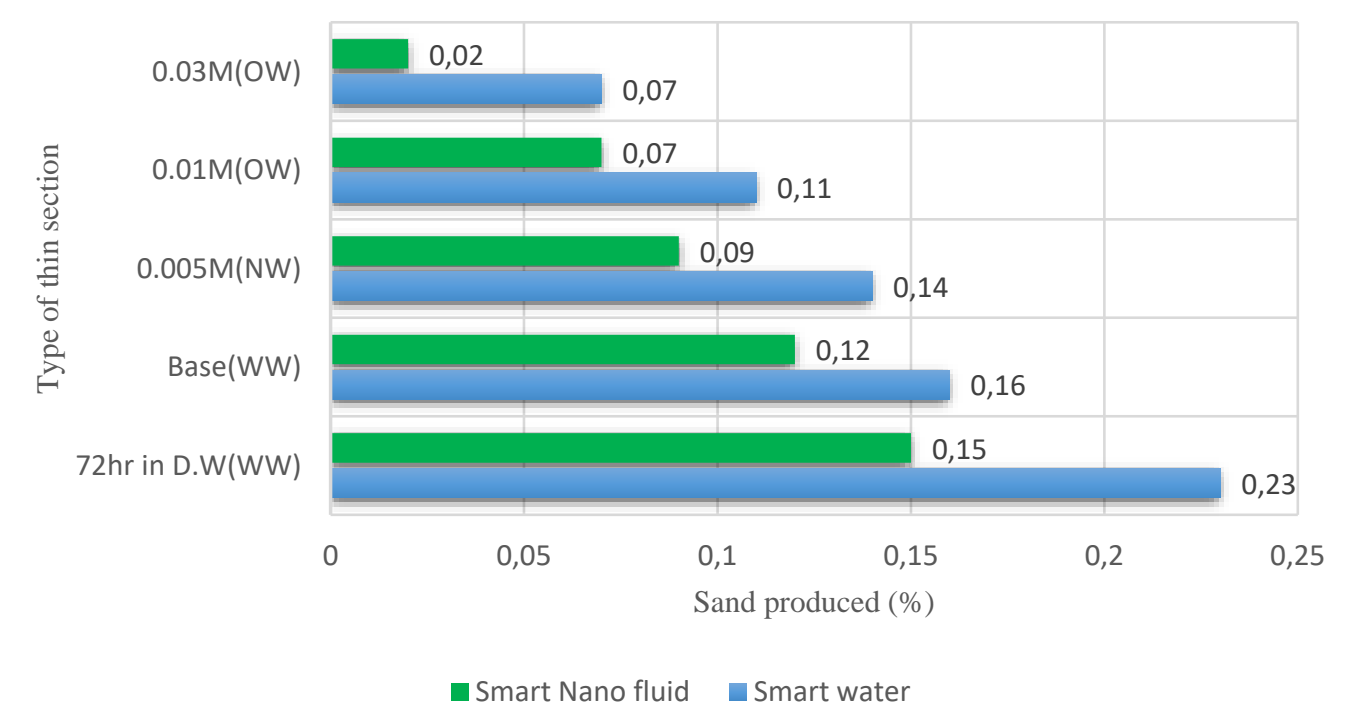

Figure 14. Sand production of different thin sections in the smart water and smart nanofluid (smart water +2000ppm $\mathrm{SiO}_{2}$ ).

The amount of sand production from the rock was significantly reduced by dispersing silica nanoparticles in smart water at stable and optimum concentrations based on the zeta potential and dynamic light scattering (DLS) test results. According to FESEM images, due to the settling and covering of the rock surface by spherical silica nanoparticles after soaking time, in addition to helping wettability alteration come closer to water-wet conditions, it prevents smart water from contact with grains and cement, thus preventing the sand production.

With regard to experimental results, the highest stress and chemical activity arising from wettability alteration of the rock surface by smart water are related to the initial phases of the experiment. With the passage of time and obtaining equilibrium at the rock surface, the amount of sand production is reduced. Besides, the results of smart nanofluid tests show that the highest sand production rate is related to the initial phases of the experiment. With the settling of silica nanoparticles on the rock surface, sand production would eventually come to an end.

Smart water containing nanoparticles (smart nanofluid) have reduced the amount of sand production by $30 \%$ compared to smart water in the water-wet thin section, $36 \%$ in the neutral-wet thin section, and 54\% in the oil-wet thin section. According to the results of a contact angle test, the smart nanofluid has caused greater water-wettability of the rock surface due to the disjoining pressure at wedge film, the accumulation of nanoparticles at the rock surface overcoming Van der Waals forces. This indicates the improvement of the injection fluid in the IOR / EOR process.

\section{Funding}

This research received no external funding.

\section{Acknowledgments}

This research has no acknowledgment.

\section{Conflicts of Interest}

The authors declare no conflict of interest. 


\section{References}

1. Yan, M.; Deng, J.; Yu, B.; Li, M.; Zhang, B.; Xiao, Q.; Tian, D. Comparative study on sanding characteristics between weakly consolidated sandstones and unconsolidated sandstones. Journal of Natural Gas Science and Engineering 2020, 76, 103183, https://doi.org/10.1016/j.jngse.2020.103183.

2. Bjørlykke, K. Chapter 2 Sandstone Diagenesis in Relation to Preservation, Destruction and Creation of Porosity. In Developments in Sedimentology, Chilingarian, G.V., Wolf, K.H., Eds. Elsevier: 1988; Vol. 41, 555-588, https://doi.org/10.1016/S0070-4571(08)70180-8.

3. Deng, F.; Yan, C.; Jia, S.; Chen, S.; Wang, L.; He, L. Influence of Sand Production in an Unconsolidated Sandstone Reservoir in a Deepwater Gas Field. Journal of Energy Resources Technology 2019, 141, https://doi.org/10.1115/1.4043132.

4. Vardoulakis, I.; Stavropoulou, M.; Papanastasiou, P. Hydro-mechanical aspects of the sand production problem. Transport in Porous Media 1996, 22, 225-244, https://doi.org/10.1007/BF01143517.

5. Morita, N.; Boyd, P.A. Typical Sand Production Problems Case Studies and Strategies for Sand Control. SPE-22739-MS 1991, 801-813, https://doi.org/10.2118/22739-MS.

6. Salehi, M.B.; Moghadam, A.M.; Marandi, S.Z. Polyacrylamide hydrogel application in sand control with compressive strength testing. Petroleum Science 2019, 16, 94-104, https://doi.org/10.1007/s12182-018-02559.

7. Rao, D.N.; Ayirala, S.C.; Abe, A.A.; Xu, W. Impact of Low-Cost Dilute Surfactants on Wettability and Relative Permeability. SPE-99609-MS 2006, 22-26, https://doi.org/10.2118/99609-MS.

8. Chen, Y.; Xie, Q.; Saeedi, A. Electrostatic characterization of -NH+-brine-kaolinite system: Implications for low salinity waterflooding in sandstone reservoirs. Journal of Petroleum Science and Engineering 2019, 179, 539-545, https://doi.org/10.1016/j.petrol.2019.04.056.

9. Schembre, J.M.; Tang, G.Q.; Kovscek, A.R. Wettability alteration and oil recovery by water imbibition at elevated temperatures. Journal of Petroleum Science and Engineering 2006, 52, 131-148, https://doi.org/10.1016/j.petrol.2006.03.017.

10. Sarkar, A.K.; Sharma, M.M. Fines migration in two-phase flow. Journal of petroleum technology 1990, 42 , 646-652, https://doi.org/10.2118/17437-PA.

11. Muecke, T.W. Formation fines and factors controlling their movement in porous media. Journal of petroleum technology 1979, 31, 144-150, https://doi.org/10.2118/7007-PA.

12. Bartels, W.B.; Mahani, H.; Berg, S.; Hassanizadeh, S.M. Literature review of low salinity waterflooding from a length and time scale perspective. Fuel 2019, 236, 338-353, https://doi.org/10.1016/j.fuel.2018.09.018.

13. Mohammadi, M.; Mahani, H. Direct insights into the pore-scale mechanism of low-salinity waterflooding in carbonates using a novel calcite microfluidic chip. Fuel 2020, 260, 116374, https://doi.org/10.1016/j.fuel.2019.116374.

14. Olayiwola, S.O.; Dejam, M. A comprehensive review on interaction of nanoparticles with low salinity water and surfactant for enhanced oil recovery in sandstone and carbonate reservoirs. Fuel 2019, 241, 1045-1057, https://doi.org/10.1016/j.fuel.2018.12.122.

15. Piñerez Torrijos, I.D.; Puntervold, T.; Strand, S.; Austad, T.; Bleivik, T.H.; Abdullah, H.I. An experimental study of the low salinity Smart Water - Polymer hybrid EOR effect in sandstone material. Journal of Petroleum Science and Engineering 2018, 164, 219-229, https://doi.org/10.1016/j.petrol.2018.01.031.

16. Moradi, S.; Isari, A.A.; Bachari, Z.; Mahmoodi, H. Combination of a new natural surfactant and smart water injection for enhanced oil recovery in carbonate rock: Synergic impacts of active ions and natural surfactant concentration. Journal of Petroleum Science and Engineering 2019, 176, 1-10, https://doi.org/10.1016/j.petrol.2019.01.043.

17. Chávez-Miyauch, T.E.; Lu, Y.; Firoozabadi, A. Low salinity water injection in Berea sandstone: Effect of wettability, interface elasticity, and acid and base functionalities. Fuel 2020, 263, 116572, https://doi.org/10.1016/j.fuel.2019.116572.

18. Li, Z.; Xu, Z.; Ayirala, S.; Yousef, A. Smartwater Effects on Wettability, Adhesion, and Oil Liberation in Carbonates. SPE Journal 2020, 25, 1771-1783, https://doi.org/10.2118/193196-PA.

19. RezaeiDoust, A.; Puntervold, T.; Strand, S.; Austad, T. Smart Water as Wettability Modifier in Carbonate and Sandstone: A Discussion of Similarities/Differences in the Chemical Mechanisms. Energy Fuels 2009, 23, 4479-4485, https://doi.org/10.1021/ef900185q.

20. Anderson, W.G. Wettability literature survey-part 3: the effects of wettability on the electrical properties of porous media. Journal of Petroleum Technology 1986, 38, 1-371, https://doi.org/10.2118/13934-PA. 
21. Khishvand, M.; Alizadeh, A.H.; Piri, M. In-situ characterization of wettability and pore-scale displacements during two- and three-phase flow in natural porous media. Advances in Water Resources 2016, 97, 279-298, https://doi.org/10.1016/j.advwatres.2016.10.009.

22. Song, J.; Wang, Q.; Shaik, I.; Puerto, M.; Bikkina, P.; Aichele, C.; Biswal, S.L.; Hirasaki, G.J. Effect of salinity, $\mathrm{Mg} 2+$ and $\mathrm{SO} 42-$ on "smart water"-induced carbonate wettability alteration in a model oil system. J. Colloid Interface Sci. 2020, 563, 145-155, https://doi.org/10.1016/j.jcis.2019.12.040.

23. Ahmadi, S.; Hosseini, M.; Tangestani, E.; Mousavi, S.E.; Niazi, M. Wettability alteration and oil recovery by spontaneous imbibition of smart water and surfactants into carbonates. Petroleum Science 2020, 17, 712-721, https://doi.org/10.1007/s12182-019-00412-1.

24. Rahimi, A.; Honarvar, B.; Safari, M. The role of salinity and aging time on carbonate reservoir in low salinity seawater and smart seawater flooding. Journal of Petroleum Science and Engineering 2020, 187, 106739, https://doi.org/10.1016/j.petrol.2019.106739.

25. Nowrouzi, I.; Manshad, A.K.; Mohammadi, A.H. Effects of dissolved binary ionic compounds and different densities of brine on interfacial tension (IFT), wettability alteration, and contact angle in smart water and carbonated smart water injection processes in carbonate oil reservoirs. J. Mol. Liq. 2018, 254, 83-92, https://doi.org/10.1016/j.molliq.2017.12.144.

26. Manshad, A.K.; Nowrouzi, I.; Mohammadi, A.H. Effects of water soluble ions on wettability alteration and contact angle in smart and carbonated smart water injection process in oil reservoirs. J. Mol. Liq. 2017, 244, 440-452, https://doi.org/10.1016/j.molliq.2017.09.011.

27. Moghadasi, R.; Rostami, A.; Hemmati-Sarapardeh, A.; Motie, M. Application of Nanosilica for inhibition of fines migration during low salinity water injection: Experimental study, mechanistic understanding, and model development. Fuel 2019, 242, 846-862, https://doi.org/10.1016/j.fuel.2019.01.053.

28. Servant, G.; Marchina, P.; Nauroy, J.-F. Near Wellbore Modeling: Sand Production Issues. SPE-109894-MS 2007, 1-9, https://doi.org/10.2118/109894-MS.

29. Newcombe, J.; McGhee, J.; Rzasa, M.J. Wettability versus displacement in water flooding in unconsolidated sand columns. Transactions of the AIME 1955, 204, 227-232, https://doi.org/10.2118/511-G.

30. Tang, G.-Q.; Morrow, N.R. Influence of brine composition and fines migration on crude oil/brine/rock interactions and oil recovery. Journal of Petroleum Science and Engineering 1999, 24, 99-111, https://doi.org/10.1016/S0920-4105(99)00034-0.

31. Dong, C.; Zhou, Y.; Chen, Q.; Zhu, C.; Li, Y.; Li, X.; Liu, Y. Effects of fluid flow rate and viscosity on gravel-pack plugging and the optimization of sand-control wells production. Petroleum Exploration and Development 2019, 46, 1251-1259, https://doi.org/10.1016/S1876-3804(19)60278-8.

32. Salama, M.M. Sand production management. J. Energy Resour. Technol. 2000, 122, 29-33, https://doi.org/10.1115/1.483158.

33. Fitzgerald, B.M.; Stephens, G.; Terwilliger, P.L. Warm Air Coking Sand Consolidation Field Results In Viscous Oil Sands. Journal of Petroleum Technology 1966, 18, 35-42, https://doi.org/10.2118/1239-PA.

34. Alakbari, F.S.; Mohyaldinn, M.E.; Muhsan, A.S.; Hasan, N.; Ganat, T. Chemical Sand Consolidation: From Polymers to Nanoparticles. Polymers 2020, 12, https://doi.org/10.3390/polym12051069.

35. Ahad, N.A.; Jami, M.; Tyson, S. A review of experimental studies on sand screen selection for unconsolidated sandstone reservoirs. Journal of Petroleum Exploration and Production Technology 2020, 10, 1675-1688, https://doi.org/10.1007/s13202-019-00826-y.

36. Arab, D.; Pourafshary, P. Nanoparticles-assisted surface charge modification of the porous medium to treat colloidal particles migration induced by low salinity water flooding. Colloids Surf. Physicochem. Eng. Aspects 2013, 436, 803-814, https://doi.org/10.1016/j.colsurfa.2013.08.022.

37. Assef, Y.; Arab, D.; Pourafshary, P. Application of nanofluid to control fines migration to improve the performance of low salinity water flooding and alkaline flooding. Journal of Petroleum Science and Engineering 2014, 124, 331-340, https://doi.org/10.1016/j.petrol.2014.09.023.

38. Nowrouzi, I.; Manshad, A.K.; Mohammadi, A.H. Effects of concentration and size of TiO2 nanoparticles on the performance of smart water in wettability alteration and oil production under spontaneous imbibition. Journal of Petroleum Science and Engineering 2019, 183, 106357 , https://doi.org/10.1016/j.petrol.2019.106357.

39. Bahri, A; Khamehchi, E. Interfacial Phenomena Effect on Sand Production Due to Optimized Smart Water with/without the Presence of Nanoparticles. Biointerface Research in Applied Chemistry 2020, 10, 66526668, https://doi.org/10.33263/BRIAC106.66526668. 
40. Ezzati, S.; Khamehchi, E. Sandstone Reservoir Wettability Alteration Due to Water Softening: Impact of Silica Nanoparticles on Sand Production Mechanism. Biointerface Research in Applied Chemistry 2020, 5 , 6328-6342, https://doi.org/10.33263/BRIAC105.63286342.

41. Bijani, M; Khamehchi, E; Ezzati, Sh. Silica Nanoparticles and pH effect on Sand Production Mechanism due to Smart Water Softening. Silica Nanoparticles and pH effect on Sand Production Mechanism due to Smart Water Softening. Letters in Applied NanoBioScience 2020, 9, 1294-1306, https://doi.org/10.33263/LIANBS93.12941306.

42. Huang, T.; Crews, J.B.; Willingham, J.R. Nanoparticles for formation fines fixation and improving performance of surfactant structure fluids. IPTC-12414-MS 2008, 1-10, https://doi.org/10.2523/IPTC-12414MS.

43. Weng, M.C.; Jeng, F.S.; Hsieh, Y.M.; Huang, T.H. A simple model for stress-induced anisotropic softening of weak sandstones. Int. J. Rock Mech. Min. Sci. 2008, 45, 155-166, https://doi.org/10.1016/j.ijrmms.2007.04.004.

44. Yuan, B.; Moghanloo, R.G.; Wang, W. Using nanofluids to control fines migration for oil recovery: Nanofluids co-injection or nanofluids pre-flush? -A comprehensive answer. Fuel 2018, 215, 474-483, https://doi.org/10.1016/j.fuel.2017.11.088.

45. Ogolo, N.C.; Olafuyi, O.A.; Onyekonwu, M. Effect of nanoparticles on migrating fines in formations. $S P E$ 155213-MS 2012, 1-12, https://doi.org/10.2118/155213-MS.

46. Hasannejad, R.; Pourafshary, P.; Vatani, A.; Sameni, A. Application of silica nanofluid to control initiation of fines migration. Petroleum Exploration and Development 2017, 44, 850-859, https://doi.org/10.1016/S1876-3804(17)30096-4.

47. Aghajanzadeh, M.R.; Ahmadi, P.; Sharifi, M.; Riazi, M. Wettability modification of oil-wet carbonate reservoirs using silica-based nanofluid: An experimental approach. Journal of Petroleum Science and Engineering 2019, 178, 700-710, https://doi.org/10.1016/j.petrol.2019.03.059.

48. Mahbubul, I.M.; Elcioglu, E.B.; Saidur, R.; Amalina, M.A. Optimization of ultrasonication period for better dispersion and stability of TiO2-water nanofluid. Ultrason. Sonochem. 2017, 37, 360-367, https://doi.org/10.1016/j.ultsonch.2017.01.024.

49. Kumar, A.; Dixit, C.K. 3 - Methods for characterization of nanoparticles. In Advances in Nanomedicine for the Delivery of Therapeutic Nucleic Acids, Nimesh, S., Chandra, R., Gupta, N., Eds. Woodhead Publishing: 2017, 43-58, https://doi.org/10.1016/B978-0-08-100557-6.00003-1.

50. Hwang, Y.; Lee, J.-K.; Lee, J.-K.; Jeong, Y.-M.; Cheong, S.-i.; Ahn, Y.-C.; Kim, S.H. Production and dispersion stability of nanoparticles in nanofluids. Powder Technol. 2008, 186, 145-153, https://doi.org/10.1016/j.powtec.2007.11.020.

51. Jarrahian, K.; Seiedi, O.; Sheykhan, M.; Sefti, M.V.; Ayatollahi, S. Wettability alteration of carbonate rocks by surfactants: A mechanistic study. Colloids Surf. Physicochem. Eng. Aspects 2012, 410, 1-10, https://doi.org/10.1016/j.colsurfa.2012.06.007.

52. Rezaei Gomari, K.A.; Hamouda, A.A. Effect of fatty acids, water composition and $\mathrm{pH}$ on the wettability alteration of calcite surface. Journal of Petroleum Science and Engineering 2006, 50, 140-150, https://doi.org/10.1016/j.petrol.2005.10.007.

53. Mamonov, A.; Puntervold, T.; Strand, S. EOR by smart water flooding in sandstone reservoirs-effect of sandstone mineralogy on initial wetting and oil recovery. SPE-187839-MS 2017, 1-19, https://doi.org/10.2118/187839-MS.

54. Austad, T. Chapter 13 - Water-Based EOR in Carbonates and Sandstones: New Chemical Understanding of the EOR Potential Using “Smart Water". In Enhanced Oil Recovery Field Case Studies, Sheng, J.J., Ed. Gulf Professional Publishing: Boston, 2013, 301-335, https://doi.org/10.1016/B978-0-12-386545-8.00013-0.

55. Rafiei, A; Khamehchi, E. Design of smart water composition based on scale minimization and its effect on wettability alteration in the presence of nanoparticles and mineral scales. Journal of Petroleum Science and Engineering 2021, 196, https://doi.org/10.1016/j.petrol.2020.107832.

56. Yousef, A.A.; Al-Salehsalah, S.H.; Al-Jawfi, M.S. New recovery method for carbonate reservoirs through tuning the injection water salinity: Smart waterflooding. SPE-143550-MS 2011, 1-16, https://doi.org/10.2118/143550-MS.

57. Xie, Q.; Saeedi, A.; Pooryousefy, E.; Liu, Y. Extended DLVO-based estimates of surface force in low salinity water flooding. J. Mol. Liq. 2016, 221, 658-665, https://doi.org/10.1016/j.molliq.2016.06.004.

58. Ju, B.; Fan, T. Wettability Alteration and Its Effects on Production in Water Flooding. Pet. Sci. Technol. 2012, 30, 1692-1703, https://doi.org/10.1080/10916466.2011.639589. 
59. Yousef, A.A.; Al-Saleh, S.; Al-Jawfi, M.S. Smart waterFlooding for carbonate reservoirs: Salinity and role of ions. SPE-141082-MS 2011, 1-11, https://doi.org/10.2118/141082-MS.

60. Lee, S.Y.; Webb, K.J.; Collins, I.; Lager, A.; Clarke, S.; O'Sullivan, M.; Routh, A.; Wang, X. Low salinity oil recovery: increasing understanding of the underlying mechanisms, https://doi.org/10.2118/129722-MS.

61. Khilar, K.C.; Fogler, H.S. The existence of a critical salt concentration for particle release. J. Colloid Interface Sci. 1984, 101, 214-224, https://doi.org/10.1016/0021-9797(84)90021-3.

62. Habibi, A.; Ahmadi, M.; Pourafshary, P.; Ayatollahi, S.; Al-Wahaibi, Y. Reduction of fines migration by nanofluids injection: an experimental study. SPE Journal 2013, 18, 309-318, https://doi.org/10.2118/144196PA.

63. Al-Anssari, S.; Barifcani, A.; Wang, S.; Maxim, L.; Iglauer, S. Wettability alteration of oil-wet carbonate by silica nanofluid. J. Colloid Interface Sci. 2016, 461, 435-442, https://doi.org/10.1016/j.jcis.2015.09.051.

64. Roustaei, A.; Moghadasi, J.; Iran, A.; Bagherzadeh, H.; Shahrabadi, A. An experimental investigation of polysilicon nanoparticles' recovery efficiencies through changes in interfacial tension and wettability alteration. SPE-156976-MS 2012, 1-7, https://doi.org/10.2118/156976-MS.

65. Shakiba, M; Khamehchi, E; Fahimifar, A; Dabir, B. A mechanistic study of smart water injection in the presence of nanoparticles for sand production control in unconsolidated sandstone reservoirs. Journal of Molecular Liquids 2020, 319, https://doi.org/10.1016/j.molliq.2020.114210.

66. Youssif, M.I.; El-Maghraby, R.M.; Saleh, S.M.; Elgibaly, A. Silica nanofluid flooding for enhanced oil recovery in sandstone rocks. Egyptian Journal of Petroleum 2018, 27, 105-110, https://doi.org/10.1016/j.ejpe.2017.01.006.

67. Kondiparty, K.; Nikolov, A.; Wu, S.; Wasan, D. Wetting and Spreading of Nanofluids on Solid Surfaces Driven by the Structural Disjoining Pressure: Statics Analysis and Experiments. Langmuir 2011, 27, 33243335, https://doi.org/10.1021/la104204b.

68. Chengara, A.; Nikolov, A.D.; Wasan, D.T.; Trokhymchuk, A.; Henderson, D. Spreading of nanofluids driven by the structural disjoining pressure gradient. J. Colloid Interface Sci. 2004, 280, 192-201, https://doi.org/10.1016/j.jcis.2004.07.005.

69. Maghzi, A.; Mohebbi, A.; Kharrat, R.; Ghazanfari, M.H. Pore-Scale Monitoring of Wettability Alteration by Silica Nanoparticles During Polymer Flooding to Heavy Oil in a Five-Spot Glass Micromodel. Transport in Porous Media 2011, 87, 653-664, https://doi.org/10.1007/s11242-010-9696-3. 